\title{
The influence of food on postural hypotension in three groups with chronic autonomic failure- clinical and therapeutic implications
}

\author{
C J Mathias, E Holly, E Armstrong, M Shareef, R Bannister
}

\begin{abstract}
The effect of a balanced liquid meal on supine and postural blood pressure (BP) responses was investigated in three groups of patients with chronic autonomic failure; 10 with associated neurological impairment (multiple system atrophy (MSA), Shy-Drager syndrome) and seven without (of which five had pure autonomic failure (PAF); and two had a deficiency of the enzyme dopamine beta hydroxylase, DBHdeficiency). All had marked postural hypotension. Subjects with normal autonomic function were also studied. In MSA and PAF food lowered supine BP substantially, with a more rapid and greater fall in PAF. After food, the levels of $\mathrm{BP}$ reached were considerably lower because of the reduced supine $B P$ and many had to be returned to the horizontal position earlier than before. Ingestion of a similar volume of water alone had no effect in MSA or PAF. In DBH deficiency, food had variable but minimal effects on BP while supine and during head-up tilt. In subjects with normal autonomic function food did not affect BP. The BP responses to food thus varied in the three groups with chronic autonomic failure. The influence of food on both supine and postural BP therefore should be considered in the clinical and laboratory assessment of autonomic dysfunction and in relation to therapeutic approaches, designed to alleviate postural hypotension.
\end{abstract}

Postural hypotension is a cardinal manifestation of autonomic failure and a fall of 20 $\mathrm{mm} \mathrm{Hg}$ systolic (or less in the presence of symptoms) requires further investigation, whereas a minimal fall often excludes autonomic dysfunction. ${ }^{1}$ A number of factors, however, can influence orthostatic hypotension. Autonomic failure patients are often worse in the morning, mainly because of nocturnal polyuria, overnight weight loss and a reduction in extracellular fluid volume; ${ }^{2}$ a warm environment (hot weather, or a hot bath) and food ingestion also worsen postural symptoms. ${ }^{3}$ Although post-prandial hypotension frequently occurs in autonomic failure, ${ }^{45}$ there have been no studies to determine if food aggravates postural hypotension. We were prompted to investigate this after two patients with mild asymptomatic postural

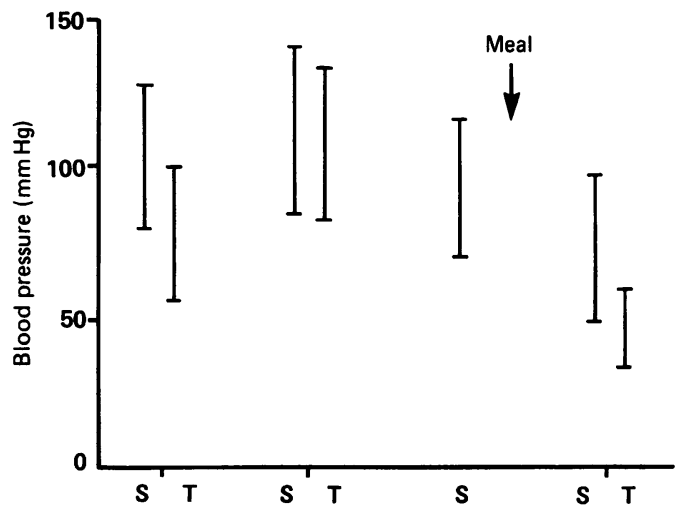

Figure 1 Systolic and diastolic blood pressure in a patient with multiple system atrophy while supine $(S)$ and after $45^{\circ}$ head-up tilt ( $T$ ) on three occasions. On the first two, food intake was not controlled; the patient had, however, not eaten on the second occasion, when the postural blood pressure fall was negligible. On the third, supine blood pressure was measured while fasting before and 45 minutes after the meal. Post-prandial tilt caused a considerable fall in blood pressure, and the patient had to be returned to the horizontal within three minutes.

hypotension on initial testing, became incapacitated when re-tilted after food ingestion (fig 1).

We report on blood pressure measurements in the supine and head-up tilt position, in three patient groups with chronic autonomic failure before and after food ingestion. Comparisons were made within the same individual, with additional observations between the three different categories.

\section{Patients and methods}

Seventeen patients with chronic autonomic failure were studied. All had symptomatic postural hypotension (over $20 \mathrm{~mm} \mathrm{Hg}$ systolic) and had evidence of sympathetic vasoconstrictor failure ${ }^{1}$ (table). Ten patients, aged 34-68, (five males), had autonomic failure with extrapyramidal, and in some pyramidal and cerebellar features, as part of multiple system atrophy (MSA) or the Shy-Drager syndrome. Five patients, aged 38-72 (two males) had autonomic failure with no other neurological abnormalities (pure autonomic failure-PAF). No cause for their autonomic failure, such as diabetes mellitus, was detected. Two patients, a brother and sister aged 29 and 23, respectively, had severe orthostatic hypotension due to an inability to convert dopamine into noradrenaline, because of the absence of the enzyme dopamine beta hydroxylase (DBH deficiency). Their clinical details and blood pressure responses to food while supine, but not after tilt, have been described previously. ${ }^{6}$ 
Table Summary of physiological and biochemical abnormalities in multiple system atrophy (MSA), pure autonomic failure (PAF) and two siblings with dopamine-betahydroxylase deficiency (DBH-defn).

\begin{tabular}{|c|c|c|c|c|}
\hline & $\begin{array}{l}M S A \\
(n=10)\end{array}$ & $\begin{array}{l}P A F \\
(n=5)\end{array}$ & $\begin{array}{l}D B H \\
\text { defn-1 }\end{array}$ & $\begin{array}{l}\text { DBH } \\
\text { defn-2 }\end{array}$ \\
\hline \\
\hline Valsalva manoeuvre & $\mathbf{A}^{+}$ & $\mathbf{A}^{\top}$ & $\stackrel{+}{A}$ & $\stackrel{+}{A}$ \\
\hline $\begin{array}{l}\text { Pressor tests } \\
\text { (mental arithmetic, cutaneous }\end{array}$ & & & & \\
\hline & A & A & A & A \\
\hline Sinus arrhythmia & A & A & $\mathbf{N}$ & $\mathbf{N}$ \\
\hline $\begin{array}{l}\text { Thermoregulatory sweating } \\
\text { (to a } 1^{\circ} \mathrm{C} \text { rise in body }\end{array}$ & & & & \\
\hline $\begin{array}{l}\text { temperature) } \\
\text { Plasma noradrenaline }(\mathrm{pg} / \mathrm{ml})\end{array}$ & - & - & + & + \\
\hline $\begin{array}{l}\text { Plasma noradrenaline }(\mathrm{pg} / \mathrm{ml}) \\
\text { - supine }\end{array}$ & $227+51$ & $72+14$ & & \\
\hline $\begin{array}{l}\text {-head-up tilt }-45^{\circ} \times 10 \mathrm{~min} \\
\text { Plasma adrenaline }(\mathrm{pg} / \mathrm{ml})\end{array}$ & $254 \pm 54$ & $61 \pm 10$ & ND & ND \\
\hline $\begin{array}{l}\text {-supine } \\
\text {-head-up tilt }-45^{\circ} \times 10 \mathrm{~min} \\
\text { Plasma dopamine }(\mathrm{pg} / \mathrm{ml})\end{array}$ & $\begin{array}{l}38 \pm 12 \\
50 \pm 18\end{array}$ & $\begin{array}{l}14 \pm 9 \\
32 \pm 20\end{array}$ & $\begin{array}{l}\text { ND } \\
\text { ND }\end{array}$ & $\begin{array}{l}\text { ND } \\
\text { ND }\end{array}$ \\
\hline - supine & $<20$ & $<20$ & 200 & 600 \\
\hline
\end{tabular}

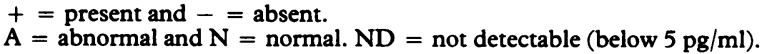

Eight subjects, aged 28-73 (four males) with normal autonomic function on physiological testing, and with no other abnormalities on further investigation, were also studied.

Measurements were performed in a clinical laboratory. Drugs which included fludrocortisone, desmopressin and dihydroergotamine, were withdrawn the day before the study. Patients reported at 1100 hours, having had a light breakfast of cereal at 0700 hours. After emptying the urinary bladder, they lay on an electrically operated tilt table. Blood pressure and heart rate were measured by an automated sphygmomanometer (Sentron Biomedical) every five minutes. Mean arterial blood pressure was calculated as a third of pulse pressure added to diastolic blood pressure. After 15 minutes of equilibration, basal supine measurements were made for the next 15 minutes. They were then tilted head-up to $45^{\circ}$ for 10 minutes, after which they were returned to the horizontal. Five minutes later, a balanced liquid meal containing commercially available Complan with glucose in a milk base $(66 \mathrm{~g}$ carbohydrate, $30 \mathrm{~g}$ protein and $15 \mathrm{~g}$ fat, $550 \mathrm{kCals}$ ), made up to $300 \mathrm{ml}$ was administered via a flexible straw with the subjects remaining supine. Measurements were continued for 45 minutes, following which subjects were retilted in an identical manner.

In two MSA and four PAF subjects the studies were repeated on another occasion, except that $300 \mathrm{ml}$ of water was administered instead of the liquid meal.

Results are expressed as means (SEM), except for the two patients with DBH deficiency whose results are provided individually. Statistical analyses included paired and unpaired $t$ tests. A p value of $<0.05$ was considered significant.

\section{Results}

$M S A$ patients Head-up tilt for 10 minutes lowered blood pressure from $161(7) / 94$ (5) to 123 (8)/77 (5) $\mathrm{mm} \mathrm{Hg}$ (both p $<0.01$ ) (fig 2) and raised heart rate [from 72 (4) to 82 (3) beats

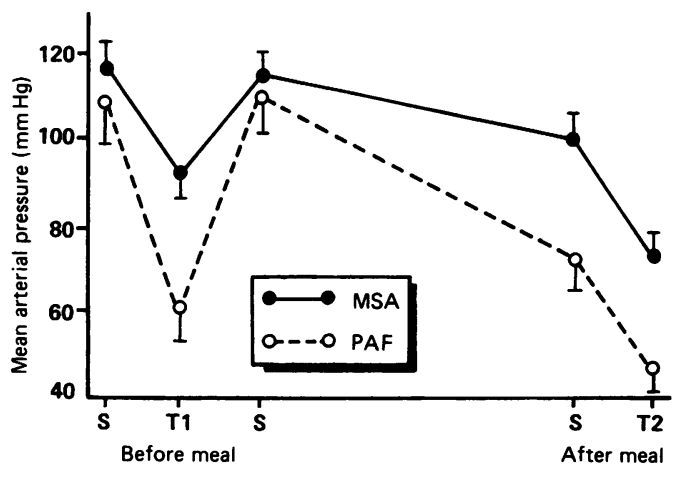

Figure 2 Average levels of mean (SEM) arterial blood pressure in patients with multiple system atrophy (MSA) and pure autonomic failure (PAF), before and during head-up tilt to $45^{\circ}$ pre-meal (T 1) on left of panel; while supine again before and 45 minutes postprandially, and after retilting ( $T 2$ ).

per minute, $\mathrm{p}<0 \cdot 25]$. After the meal, blood pressure progressively fell in nine of the 10 patients (fig 3), with little further fall after 20 minutes. Heart rate was 75 (3) beats per minute before and the highest level was 81 (3) beats per minute at 40 minutes (NS). After 45 minutes, head-up tilt caused a similar fall in blood pressure (fig 4), but to considerably lower levels [100 (8)/60 (6) $\mathrm{mm} \mathrm{Hg}$, each $\mathrm{p}<0.05]$. Five patients could not tolerate the tilt and had to be returned to the horizontal within five minutes. None had symptoms when initially tilted.

$P A F$ patients Their supine blood pressure was marginally lower than the MSA patients. After head-up tilt for 10 minutes, blood pressure fell, from 153 (13)/85 (9) to 74 (6)/51 (8), (both $\mathrm{p}<0.01$ ) (fig 2), to levels lower than in the MSA patients. Heart rate was unchanged [74 (5) to 76 (4) beats per minute]. After the meal there was a rapid and substantial fall in blood pressure in all patients within $10 \mathrm{~min}$ utes. Heart rate was 73 (5) before and the highest level was 81 (4) beats per minute at 25 minutes (NS). Post meal head-up tilt caused a smaller postural fall in blood pressure (fig 4), but as in the MSA patients, this was from a considerably lower supine level, and the blood pressure fell to even lower levels on tilting than previously [66 (5)/38 (3) $\mathrm{mm} \mathrm{Hg}$. All became more symptomatic and had to be returned to the horizontal rapidly.

$D B H$ deficiency patients Their supine blood pressure (133/85 and $121 / 71 \mathrm{~mm} \mathrm{Hg}$ ) was lower than in the MSA and PAF patients. Head-up tilt lowered blood pressure to $110 / 71$ and $83 / 44 \mathrm{~mm} \mathrm{Hg}$ respectively with a rise in heart rate from 44 and 72 , to 64 and 87 beats per minute respectively. After the meal, supine blood pressure fell in patient 1 to $120 / 75$ $\mathrm{mm} \mathrm{Hg}$ and rose in patient 2 to $129 / 82 \mathrm{~mm} \mathrm{Hg}$. Post-prandial tilt only lowered diastolic blood pressure in patient 1 (to $123 / 58 \mathrm{~mm} \mathrm{Hg}$ ); in patient 2 the blood pressure was higher than pre-prandial levels $(102 / 57 \mathrm{~mm} \mathrm{Hg})$. Heart rate rose from 50 to 64 and 64 to $92 \mathrm{~m}$ beats per minute respectively. Patient 1 was minimally symptomatic during the first tilt, with no change following food; patient 2 became less symptomatic when tilted after food. 


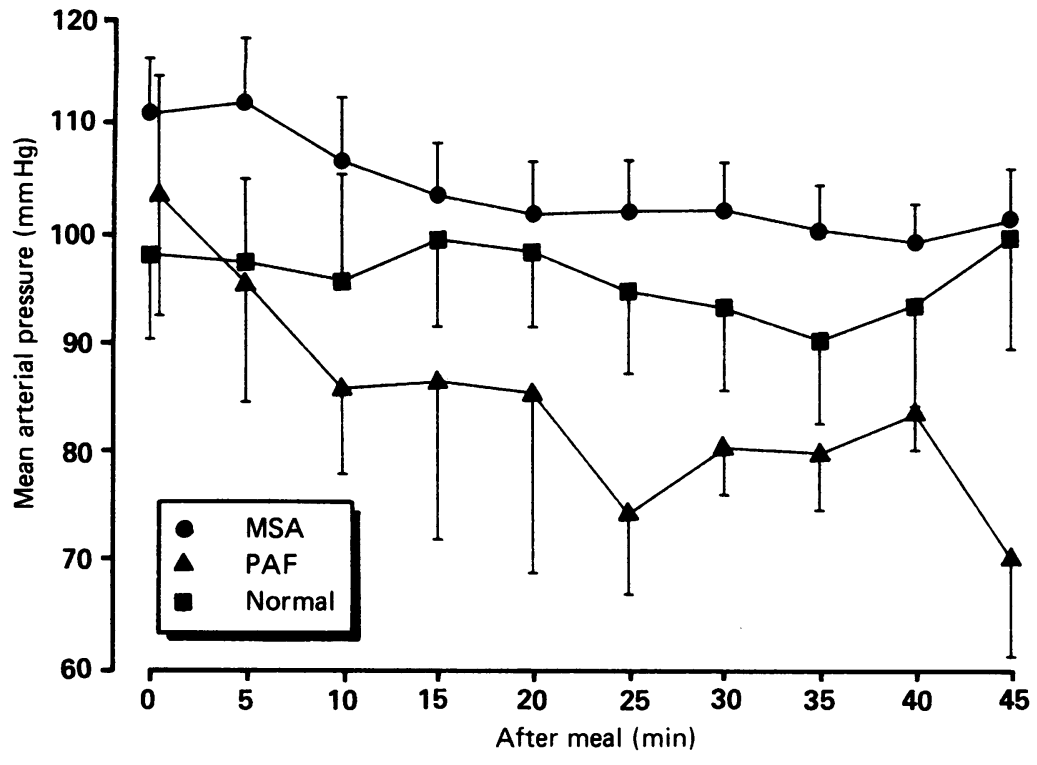

Figure 3 Mean (SEM) arterial pressure in subjects with multiple system atrophy $(M S A)$, pure autonomic failure $(P A F)$ and normal autonomic function before $(0)$ and at intervals after a liquid meal.

Subjects with normal autonomic function There was no fall in blood pressure during head-up tilt either before or after the meal (fig 4). Food did not affect supine blood pressure (fig 3).

Effect of wateringestion In the six patients who were restudied, water had no effect on supine blood pressure [from $152(14) / 88$ (8) to 161 (12)/90 (5) at 45 minutes] and the degree of postural hypotension was similar to the prewater values [to $81(7) / 50(6)$ pre-water and to $79(8) / 48$ (5) $\mathrm{mm} \mathrm{Hg}$ after water].

\section{Discussion}

The effect of food on blood pressure was recognised in 1953 by $\mathrm{Smirk}^{7}$ who observed that post-prandial supine, sitting and standing blood pressures were lower in hypertensive

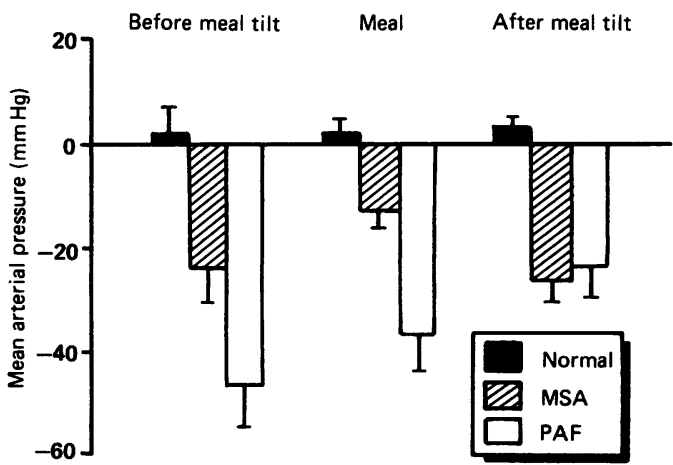

Figure 4 Absolute changes in mean (SEM) arterial pressure in subjects with normal autonomic function, multiple system atrophy (MSA) and pure autonomic failure (PAF), during head-up tilt before a meal, after failure (PAF), during head-up tilt before a meal, after
the meal while supine, and when retilted after a meal. Comparison with fig 2 indicates that the degree of postural fall alone is misleading, as in the PAF patients, in whom there is a smaller supine post-prandial blood pressure fall. In the majority the pressure, however, fell to considerably lower levels on tilt post-prandially, because of a lower supine pressure. patients given the ganglionic blocker, pentolinium. Post-prandial hypotension in a patient with autonomic failure and Parkinson's disease was first reported in 1972 by Seyer-Hansen ${ }^{8}$ and this has been confirmed in different centres in larger groups of patients with primary autonomic failure. ${ }^{45}$ In these studies patients were either sitting or lying horizontally, the effect of food on postural hypotension was not determined and it was not possible to assess differences between the groups with chronic autonomic failure. In our studies the post-prandial fall in supine blood pressure was faster and fell to lower levels in the PAF patients. Food ingestion aggravated the symptoms of postural hypotension in both MSA and PAF, and their blood pressure during tilt fell to lower levels post-prandially. This, however, was more noticeable in the MSA patients, few of whom initially had symptoms on tilting. These findings cannot be attributed to repeated tilting, which can activate the renin-angiotensinaldosterone system, ${ }^{910}$ and by the direct pressor effects of angiotensin-II and subsequent salt and water retention reduce the postural fall in blood pressure. Furthermore, a similar volume of water did not change either supine blood pressure or the degree of postural hypotension. The observed effects therefore appear to be directly related to the ingestion of food.

Food intake, even while supine, results in a number of hormonal, autonomic and haemodynamic changes. Blood pressure is maintained in normal subjects, in whom there is a rise in cardiac output, skeletal muscle vascular resistance and plasma noradrenaline levels, the latter indicating sympatho-neural activation ${ }^{5}$ presumably in response to splanchnic vasodilatation. These compensatory responses are impaired or absent in autonomic failure..$^{511}$ Vasodilatatory gut peptides probably play an important role, as inhibition of peptide release by the somatostatin analogue Octreotide, prevents glucose and food induced hypotension in primary and secondary autonomic failure. ${ }^{1112}$

The quantitative differences in blood pressure between MSA and PAF after food, warrant discussion. Both had sympathetic failure, which may have been more severe in PAF as their resting levels of plasma noradrenaline were considerably lower (as previously observed), ${ }^{13}$ and their blood pressure fell to lower levels on head-up tilt before food. This may have made them more prone to the hypotensive effects of vasodilatatory gut peptides released during food ingestion. Furthermore, there is evidence of differential release of gut/pancreatic peptides in these two groups. In PAF, basal gastrin levels are higher, and rise to a greater extent after food. ${ }^{14}$ Studies in progress indicate similar basal insulin levels but a greater rise in PAF than in MSA after an identical liquid meal challenge; this is not due to a differential absorption of glucose. Exogenous insulin lowers blood pressure in autonomic failure ${ }^{15}$ which may partly explain the greater hypotensive effect of food in PAF.

There may have been additional differences between the groups despite the common finding 
of sympathetic failure. The two with $\mathrm{DBH}$ deficiency had severe adrenergic failure but did not have substantial post-prandial hypotension. In one, the blood pressure was marginally worse after food while the other improved, in keeping with their symptoms. Despite the absence of noradrenaline and adrenaline, they were probably capable of neurally-mediated release of dopamine, as their sympathetic nerve terminals were otherwise intact, as confirmed by immunohistochemical and electronmicroscopical studies of skin tissues, where the distribution of peptides, including vasoconstrictor peptides such as Neuropeptide $Y$ was preserved, as in normal subjects. ${ }^{6}$ Neuronal impulses in response to food may have released other co-transmitters from sympathetic nerve endings, such as adenosine triphosphate (ATP), ${ }^{16}$ which induced vasoconstriction in certain vascular beds and helped maintain blood pressure. Furthermore, unlike the majority of the other MSA and PAF patients, they both had a functionally intact parasympathetic nervous system, and the ability to increase heart rate and cardiac output may have also contributed. Aspects such as gastric emptying and subsequent absorption of nutrients need to be considered, although previous studies suggest that these are unlikely to be major factors to explain the difference. ${ }^{5}$

The relationship between food and postural hypotension raises a number of clinical issues. A postural fall in blood pressure without the stimulus of food, may be dismissed as being slight, as in our two earlier patients (fig 1). This may not readily be determined from the history, as the quantity and composition of food influences post-prandial hypotension. In autonomic failure patients, protein has minimal effects on blood pressure, lipid causes a smaller and shorter lasting hypotension, while carbohydrate is the most effective in lowering blood pressure; ${ }^{17}$ the latter may be linked to a greater release of vasodilatatory peptides including insulin. ${ }^{15}$ Substances ingested with or after food, such as caffeine,$^{18}$ may reduce the blood pressure fall. A number of factors may therefore obscure the relationship between food ingestion and worsening of postural hypotension, which emphasises the need for objective assessment. This is of importance in the management of postural hypotension, as drugs which reduce postural hypotension may have their benefit negated by post-prandial hypotension, as has been shown with dihydroergotamine. ${ }^{19}$ There is clearly a need for drugs, or drug combinations, which will prevent the hypotensive effects of both stimuli.

Our observations probably apply to other groups, such as the elderly, who may have both postural ${ }^{20}$ and post-prandial ${ }^{2122}$ hypotension. A third of elderly subjects have post-prandial hypotension of over $20 \mathrm{~mm} \mathrm{Hg}$ systolic, with a greater fall when the initial pressure is higher. ${ }^{21}$ Blood pressure in the elderly after antihypertensive treatment (with nitrendipine and hydrochlorothiazide) falls to even lower levels after glucose ingestion. ${ }^{23}$ Food therefore has the potential, especially with hypotensive agents (which may include nitrates and beta-adrener- gic blockers in ischaemic heart disease), to lower blood pressure further and cause or aggravate postural hypotension. This may contribute to syncope; and myocardial ischaemia and strokes if coronary and cerebrovascular disease is co-existent.

We therefore conclude that food lowers blood pressure to a varying extent in different groups with autonomic failure and that its influence should be considered in the investigation and management of autonomic dysfunction. The liquid meal we used has the advantage of providing similar food components and calories to standard test meals. It is easier to prepare and administer, especially in the supine position. It also avoids the high osmotic load of an isocaloric solution of glucose. Our approach therefore may be a practical and effective method of determining, within the autonomic laboratory, the degree of postprandial hypotension and its potential effects on postural hypotension.

CJM thanks the Wellcome Trust and the Brain Research Trust for their support, and Miss Tina Holmes for typing the manuscript.

1 Bannister R, Mathias CJ. Testing autonomic reflexes. In: Bannister R, ed. Autonomic failure: a textbook of disorders Bannister R, ed. Autonomic failure: a textbook of disorders of the autonomic nervous system.
University Press, 1988:289-307.

2 Mathias CJ, Fosbraey P, da Costa DF, Thornley A, Bannister $R$. Desmopressin reduces nocturnal polyuria, reverses overnight weight loss and improves morning postural hypotension in autonomic failure. $B M J 1986$; 293:353-4

3 Bannister R, Mathias CJ. Management of postural hypotension. In: Bannister R, ed. Autonomic failure: a textbook of disorder of the autonomic nervous system, 2 nd ed. Oxford: Oxford University Press, 1988:659-95.

4 Robertson D, Wade D, Robertson RM. Post-prandial alterations in cardiovascular haemodynamics in autonomic dysfunctional states. Am J Cardiol 1981:48: nomic dyst

5 Mathias CJ, da Costa DF, Fosbraey P, et al. Cardiovascular, biochemical and hormonal changes during food-induced hypotension in chro $1989 ; 94: 255-69$.

6 Mathias CJ, Bannister RB, Cortelli P, et al. Clinical, autonomic and therapeutic observations in two siblings with postural hypotension and sympathetic failure due to an inability to synthesize noradrenaline from dopamine because of a deficiency of dopamine beta hydroxylase. Ouart J Med 1990;278:617-33.

7 Smirk FH. Action of a new methonium compound in arterial hypertension; Pentamethylene 1:5-bis- $\mathrm{N}$-(N-methylpyrrolidinium) bitartrate (M and B 2050A). Lancet 1953; i:457.

8 Seyer-Hansen K. Post-prandial hypotension. BMJ 1977; 2:1262.

9 Mathias CJ, Christensen NJ, Corbett JL, Frankel HL, Goodwin TJ, Peart WS. Plasma catecholamines, plasma renin activity and plasma aldosterone in tetraplegic man, renin activity and plasma aldosterone in tetraplegic man,
horizontal and tilted. Clin Sci and Mol Med 1975;49: horizon $291-9$.

10 Bannister R, Sever PS, Gross M. Cardiovascular reflexes and biochemical responses in progressive autonomic failure. Brain 1977;100:327-44

11 Raimbach SJ, Cortelli P, Kooner JS, Bannister R, Bloom SR, Mathias CJ. Prevention of glucose induced hypotension by the somatostatin analogue, (Octreotide (SMS 201995) in chronic autonomic failure-haemodynamic and hormonal changes. Clin Sci 1989;77:623-8.

12 Hoeldtke RD, O-Dorisio TM, Boden G. Treatment of autonomic neuropathy with a somatostatin analogue SMS-201-995. Lancet 1986;ii:602-5.

13 Ziegler MG, Lake CR, Kopin IJ. The sympathetic-nervoussystem defect in primary orthostatic hypotension. New system defect in primary or

14 Polinsky RJ, Taylor IL, Weise V, Kopin IJ. Gastrin responses in patients with adrenergic insufficiency. responses in patients with adrenergic ins
$J$ Neurol Neurosurg Psychiatry 1988;51:67-71.

15 Mathias CJ, da Costa DF, Fosbraey P, Christensen NJ, Bannister R. Hyoptensive and sedative effects of insulin in Bannister R. Hyoptensive and sedative effects
autonomic failure. BMJ 1977;295:161-3.

16 Warland JJI, Burnstock G. Effects of reserpine and 6hydroxydopamine on the adrenergic and purinergic com- 
ponents of sympathetic nerve responses of the rabbit saphenous artery. $\mathrm{Br} J$ Pharmac 1987;92:871-80.

17 Mathias CJ, da Costa D, Fosbraey P, McIntosh C, Bannister R. Factors contributing to food-induced hypotension in patients with autonomic dysfunction. In: Vanhoutte PM ed. Vasodilatation. Vascular smooth muscle, peptides, autonomic nerves and endothelium. New York: Raven Press, 1988:351-6.

18 Onrot J, Goldberg MR, Biaggioni I, Hollister AS, Kincaid D, Robertson D. Haemodynamic and humoral effects of caffeine in autonomic failure. Therapeutic implications for post-prandial hypotension. $N$ Engl J Med 1986;313: 549-54.

19 Hoeldtke RL, Cavanaugh ST, Hughes JD, Polansky M. Treatment of orthostatic hypotension with dihydro- ergotamine and caffeine. Ann Int Med 1986;105:168-73. 20 Clark ANG. Postural hypotension in the elderly. BMJ 1987;295:683.

21 Lipsitz LA. Abnormalities in blood pressure homeostasis that contribute to falls in the elderly. Clinics in Geriatric Med 1985;i:637-45.

22 Robinson BJ, Johnson RH, Lambie BG, Palmer KT. Autonomic responses to glucose ingestion in elderly subjects with orthostatic hyoptension. Age Ageing 1985; 14:165-73.

23 Jansen RWMM, van Lier HJJ, Hoefnagels WHL. Effects of nitrendipine and hydrochlorothiazide on post-prandial blood pressure reduction and carbohydrate metabolism in hypertensive patients over 70 years of age. $J$ Cardiovasc hypertensive patients over 70 years of
Pharmacol 1988;12:(suppl 14), s59-63. 